\title{
MEDIAÇÃO NO ENSINO MÉDIO PÚBLICO: \\ UMA ABORDAGEM INTERDISCIPLINAR ENTRE O DIREITO À EDUCAÇÃO \\ E A ANTROPOLOGIA JURÍDICA, A PARTIR DO PENSAMENTO DE ÉTIENNE LE ROY
}

MEDIATION IN PUBLIC HIGH SCHOOL: AN INTERDISCIPLINARY APPROACH BETWEEN

EDUCATION LAW AND LEGAL ANTHROPOLOGY, FROM THE THOUGHT OF ÉTIENNE LE ROY

\section{Marcia Aparecida da Silva Annunciato*}

\begin{abstract}
Resumo:
Nesta pesquisa interdisciplinar entre o direito à Educação, em seu âmbito constitucional, e a Antropologia Jurídica, a partir da Teoria do Multijuridismo proposta por Étienne Le Roy, buscou-se sustentar a hipótese de que em relações sociais continuadas, a mediação ocorre mais nos limites dos modelos de conduta e comportamento e sistemas de disposições duráveis do que da regulação estatal. $\mathrm{O}$ artigo desenvolve-se por meio da análise comparativa entre dispositivos legais de interesse do ensino médio público e os principais elementos do referencial teórico, em especial a noção de juridicidade e a mediação. Os resultados obtidos, ainda que parciais, indicam que a comprovação da hipótese inicial demanda maior aprofundamento teórico e pesquisa de campo. Contudo, os mesmos resultados indicam o grande potencial de contribuição da obra de Étienne Le Roy para o desvelamento de novas formas de abordagem e concreção da regulação estatal da Educação do Brasil.
\end{abstract}

Palavras-chave: Ensino médio público. Étienne Le Roy. Interdisciplinaridade. Juridicidade. Mediação. Teoria do Multijuridismo.

\begin{abstract}
:
In this interdisciplinary research between the right to Education, in its constitutional scope, and Legal Anthropology, based on the Theory of Multijuridism proposed by Étienne Le Roy, it was tried to support the hypothesis that in continuous social relations, mediation occurs more within the limits models of conduct and behavior and systems of durable arrangements than those of state regulation. The article develops through the comparative analysis between legal devices of public high school interest and the main elements of the theoretical reference, especially the notion of juridicity and mediation. However, the same results point to the great contribution potential of Étienne Le Roy's work to the unveiling of new approaches and concretion of state regulation of complex social issues such as the Brazilian educational system.
\end{abstract}

Keywords: High school. Étienne Le Roy. Interdisciplinary research. Juridicity. Mediation. Theory of Multijuridism.

* Mestre em Direito do Estado pela Faculdade de Direito da Universidade de São Paulo. E-mail: marcia@ annunciato.adv.br. 


\section{Introdução}

Partindo da hipótese de que em relações sociais continuadas a mediação ocorre mais nos limites dos costumes e dos hábitos do que das regras do direito positivo, busca-se por meio deste artigo $^{1}$ apresentar os resultados obtidos numa pesquisa interdisciplinar entre o direito à Educação, no âmbito do Direito Constitucional e a Antropologia Jurídica, utilizando como referencial teórico a Teoria do Multijuridismo proposta pelo antropólogo do direito, francês, Étienne Le Roy. ${ }^{2}$

A respeito da Teoria do Multijuridismo destaca-se que conforme Villas Bôas Filho (2014, p. 291) a obra de Étienne Le Roy, embora pouco conhecida no Brasil, apresenta um grande potencial heurístico para a compreensão da regulação jurídica, sobretudo, em um diálogo intercultural, em ambientes sociais como o brasileiro.

A investigação realizou-se pelo método comparativo entre dispositivos de lei de interesse do ensino médio público e os principais elementos do arcabouço teórico.

Para apresentação dos resultados da pesquisa, este artigo divide-se em dois capítulos:

O primeiro capítulo dedica-se a uma breve apresentação do pensamento de Étienne Le Roy, com destaque para a noção de juridicidade, elemento essencial na sua obra, a complementaridade entre o direito positivo e a juridicidade, e o fluxo de passagem do que está na esfera da juridicidade para o direito oficial.

Ao final deste capítulo, descrevem-se os resultados relativos à compatibilização da pesquisa interdisciplinar, através da análise de cinco artigos da Lei de Diretrizes e Bases da Educação (Lei n. 9.394/1996), sob o enfoque dos principais elementos da Teoria do Multijuridismo.

O segundo capítulo examina quatro dispositivos de lei relativos ao ensino médio público, à luz dos modelos de mediação propostos por Le Roy, traçando um panorama do desenvolvimento do conceito de mediação na obra do autor e apresentando as soluções alcançadas em quatro cenários de análise.

Este artigo deriva da dissertação de mestrado, com o mesmo título, sob orientação da Professora Doutora Eunice Aparecida de Jesus Prudente, da Faculdade de Direito da Universidade de São Paulo, defendida e aprovada em 22 de fevereiro de 2019.

2 Étienne Le Roy é professor emérito de antropologia de direito, doutor em direito e antropologia. Foi professor da Faculdade de Direito e Economia de Paris 1 (Panthéon-Sorbonne), pesquisador do Centro Nacional de Pesquisa Científica (CNRS) e diretor do Laboratório de Antropologia Jurídica de Paris. 
2. Multijuridismo: uma teoria jurídica intercultural

A Teoria do Multijuridismo tem como ideia central a noção de juridicidade, descrita no livro Le jeu des lois: une anthropologie "dynamique” du Droit, publicado em 1999.

Sob a ótica do pesquisador austríaco Christoph Eberhard ${ }^{3}$ (2002, p. 503) a Teoria do Multijuridismo de Le Roy é uma teoria jurídica intercultural, ancorada na tradição ocidental que pode trazer uma valiosa contribuição para compreensão da complexidade do fenômeno jurídico, em diferentes sociedades.

\subsection{Direito e juridicidade: uma relação de complementaridade}

Direito é definido por Étienne Le Roy como um mecanismo específico de regulação, desenvolvido historicamente pelas sociedades ocidentais modernas e juridicidade como um instrumento fundamental de especificação do campo jurídico como distinto, tanto do âmbito do direito em sentido estrito, como do âmbito social não jurídico.

O termo juridicidade (juridicité), embora receba críticas de alguns autores que consideram se tratar de uma simples mudança semântica, Villas Bôas Filho (2014, p. 291), entende que "juridicidade" como conceituado por Étienne Le Roy tem maior capacidade de explicitar o etnocentrismo e desvelar outras formas de regulação jurídica.

Diante disso, conforme ressalta Villas Bôas Filho (2015, p. 167) a preocupação de Le Roy é conceber uma noção de juridicidade, como uma forma de regulação que engloba o direito, não etnocêntrica, capaz de desenvolver uma genuína abordagem intercultural.

Ainda acerca da concepção de direito como mecanismo específico de regulação, desenvolvido, historicamente, pelas sociedades ocidentais modernas, Le Roy (2012, p. 291) propõe que se faça uma "leitura epistemológica da vida jurídica" e, para isso, que se admita que o direito não é autônomo e nem mesmo universal ou isento de efeitos sociais.

Neste enquadramento, para construção do conceito de juridicidade, partindo de duas proposições deduzidas pelo sociólogo francês Jean Carbonnier, a primeira, de que o direito é maior que as fontes formais do direito, e, a segunda, que o direito é menor que o conjunto das relações entre os homens, Le Roy (2012, p. 291) acrescenta uma terceira,

Christoph Eberhard é antropólogo do direito, nascido na Áustria e radicado na França, pesquisador independente e professor. Disponível em: https://www.linkedin.com/in/christoph-eberhard-ba2b9623/em. Acesso em: 13 out. 2018. 
a juridicidade, como maior que a concepção do direito desenvolvido pelas sociedades ocidentais modernas, incluindo-a no todo.

A respeito das proposições de Jean Carbonnier, Le Roy (2012, p. 315) explicita que aborda a juridicidade para além da concepção do direito positivo, excedendo sua ligação substancial com o monopólio estatal de violência legítima.

Para Le Roy (2012, p. 315), o direito é um subproduto da juridicidade, ou mais precisamente, como uma aplicação particular de expressão de cada sociedade. Segundo o autor, o direito deve ser interpretado como a passagem de tudo que é instituído na esfera da juridicidade, em condições de perenidade, legitimidade e autoridade do órgão beneficiado.

Nessa perspectiva, Le Roy (2012, p. 315) define que um traço diacrítico, um sinal que distingue, dividido pelo direito e pela juridicidade é a sanção que reconhece o caráter obrigatório da norma invocada em autoridade, momento em que é estabelecida e se torna invocável e palpável.

Étienne Le Roy (2012, p. 316) enfatiza que a juridicidade não pressupõe um abandono de espaço pelo direito, mas, sim, uma ocupação pelos costumes, usos e hábitos reconhecidos como sancionados por outras culturas, tais como: o li (costume, aplicável aos nobres) e o fa (modelo de punição aplicável aos comuns e escravos) chinês, o dharma (lei natural ou cósmica) hindu e os habitus africanos ou oceânicos (conjunto de normas que o homem deve seguir), entre outros.

Desse cenário, pode-se, segundo Le Roy (2012, p. 316), extrair as quatro propriedades divididas pela juridicidade e pelo direito:

A primeira propriedade que considera a juridicidade e o direito como dois conjuntos normativos que correspondem a mundos próprios, com uma visão de mundo institucionalizado com o direito e mundos diferentemente regularizados, numa grande proporção que pode ser multiplicada, sem qualquer programação.

A segunda propriedade que diz respeito à divisão pelo direito e pela juridicidade dos mesmos fundamentos, sobre as mesmas bases normativas, quais sejam: as normas gerais e impessoais (NGI), os modelos de condutas e de comportamentos (MCC) e os sistemas de disposições duráveis (SDD).

Nesse raciocínio, Le Roy (2012, p. 317) exemplifica que, a partir de montagens originais entre os conjuntos normativos da juridicidade e do direito, enquanto o direito civil e o common law preferem o direito, o li chinês e os habitus africanos posicionam-se na juridicidade.

No que se refere à denominação dos três fundamentos da juridicidade, Villas Bôas Filho (2017, p. 1.121) destaca que, após afirmar que lei, costume e habitus constituiriam os "fundamentos do Direito na França", Le Roy propôs a substituição de lei por "normas gerais impessoais" (NGI), de costumes por modelos de condutas e 
comportamentos (MCC) e de habitus ${ }^{4}$ por "sistemas de disposições duráveis" (SDD), no intuito de desenvolver, a partir dessas categorias gerais descritivas, uma análise antropológica intercultural.

A terceira propriedade compartilhada entre o direito e a juridicidade, de acordo com Le Roy (2012, p. 317) refere-se à organização de ambos os conjuntos normativos em montagens originais dos quatro ordenamentos jurídicos.

Nesse quadro, enquanto o direito apoia-se em um modo imposto em razão de sua concepção de ordem jurídica, como instância particular autônoma, a juridicidade, na condição de instância heterônoma, privilegia a ordem aceita, a partir da diversidade das funções que podem preencher os limites do social, do religioso, ou da economia.

Quanto à quarta propriedade dividida entre a juridicidade e o direito, esta consiste no fato de que ambos se apoiam na convenção como modo comum de elaboração da norma/solução.

Nesse sentido, Le Roy (2012, p. 317) explicita que na ausência de regra legislativa ou regulamentar, mesmo na experiência jurídica ocidental, largamente codificada, a regra é o acordo convencional de vontades, exemplificado pelo autor, através do artigo 1.134 do Código Civil francês, vigente até 2015. ${ }^{5}$

A esse respeito, Villas Bôas Filho (2017, p. 295) enfatiza que a relação de complementaridade entre o direito e a juridicidade atribuída por Le Roy, se expressa no fato de ser a juridicidade uma espécie "englobante" do direito, entendido como uma forma específica de concreção do fenômeno mais amplo, designada, por convenção, de juridicidade.

\subsection{Juridicidade: fundamentos e representação}

De acordo com Le Roy (2012, p. 316) os três fundamentos da juridicidade: as normas gerais e impessoais (NGI), os modelos de conduta e de comportamento (MCC) e os sistemas de disposições duráveis (SDD), vistos como dimensões regulatórias que se articulam e se legitimam no âmbito das tradições jurídicas de cada sociedade compõem o denominado "Tripé jurídico", representado pela figura de um iceberg.

4 A noção de habitus mobilizada por Pierre Bourdieu (2015, p. XLII) seria um conjunto de esquemas implantados desde a primeira educação familiar, e constantemente repostos e reatualizados ao longo da trajetória social restante. Étienne Le Roy analisa o conceito de habitus e especifica seu posicionamento diante do de Bourdieu. Villas Bôas Filho (2015, p. 180). A regulação jurídica para além de sua forma ocidental de expressão: uma abordagem a partir de Étienne Le Roy.

5 “Article 1134 Les conventions légalement formées tiennent lieu de loi à ceux qui les ont faites". Código Civil Francês, na versão consolidada em 2 de março de 2017, vigente: "Article 1109 Le contrat est consensuel lorsqu'il se forme par le seul échange des consentements quel qu'en soit le mode d'expression". (FRANCE, 2015). 
Nesse horizonte, segundo Le Roy a tradição ocidental aparece na figura do iceberg da seguinte forma: as normas gerais e impessoais (NGI), ou seja, o direito positivado, na parte emergida, os modelos de condutas e de comportamento (MCC) na linha de flutuação e os sistemas de disposições duráveis (SDD) imersos nas práticas sociais cotidianas, conforme representado pela figura (VILLAS BÔAS FILHO, 2015, p. 180) abaixo:

\title{
Figura 1 - ICEBERG JURÍDICO TRIPÉ JURÍDICO NA TRADIÇÃO OCIDENTAL
}

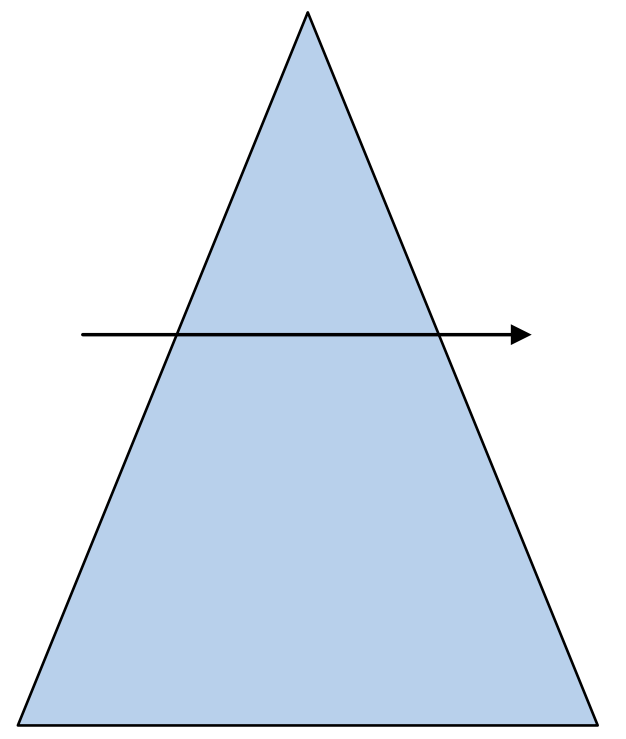

\author{
EMERGIDA - normas gerais e \\ impessoais (NGI)
}

LINHA DE FLUTUAÇÃO modelos de condutas e de comportamentos (MCC)

IMERSOS - sistemas de disposições duráveis (SDD)

À vista disso, salienta-se que os três fundamentos da juridicidade que compõem o "Tripé jurídico" não são redutíveis ou hierarquizáveis, mutuamente, e que conformariam o campo do que é jurídico, a partir de vários modos de articulação.

Acerca das possíveis articulações pelos três fundamentos da juridicidade - NGI, MCC e SDD - Le Roy propõe, a título exemplificativo, mais pedagógico do que científico, um quadro comparativo, não exaustivo, entre quatro tradições jurídicas, a saber: 


\section{Quadro resumo (VILLAS BÔAS FILHO, 2015, p. 181) da articulação do "Tripé jurídico" em diferentes tradições jurídicas:}

\begin{tabular}{|l|c|c|c|}
\hline $\begin{array}{c}\text { TRADIÇÕES } \\
\text { JURÍDICAS }\end{array}$ & $\begin{array}{c}\text { FUNDAMENTO } \\
\text { PRINCIPAL }\end{array}$ & $\begin{array}{c}\text { FUNDAMENTO } \\
\text { SECUNDÁRIO }\end{array}$ & $\begin{array}{c}\text { FUNDAMENTO } \\
\text { TERCIÁRIO }\end{array}$ \\
\hline Ocidental/cristã & NGI & MCC & SDD \\
\hline Africana/animista & MCC & SDD & NGI \\
\hline Asiática/ confuciana & SDD & MCC & NGI \\
\hline Árabe/muçulmana & NGI & SDD & MCC \\
\hline
\end{tabular}

Nas palavras de Villas Bôas Filho (2015, p. 181), esse quadro ilustra concretamente a tese de Le Roy no sentido de que os três fundamentos propostos: normas gerais e impessoais (NGI), modelos de condutas e comportamentos (MCC) e sistemas de disposições duráveis (SDD) são inerentes e estão presentes em todas as culturas, independentemente das montagens que se façam.

No mesmo sentido, Christoph Eberhard (2002, p. 517) ressalta que os três fundamentos (os três "pés") contribuem para a reprodução da humanidade em todas as sociedades, mas não são valorizados da mesma forma, o que é exemplificado pelo autor, no horizonte da África francófona, em relação à transferência do modelo de estado francês para as ex-colônias africanas e as consequências negativas percebidas na atualidade.

Em síntese, pensar a juridicidade e o direito como conjuntos normativos pertencentes a mundos próprios, o direito com uma visão de mundo institucionalizado e a juridicidade com uma visão de mundos diferentemente regulados; que se organizam, de maneira original e que têm como regra o acordo de vontades, através de um processo dialogal, não autoritário (a mediação), pode representar uma nova forma de reflexão sobre o direito, no contexto ocidental contemporâneo.

\subsection{Pontos de aproximação entre os dois campos disciplinares}

Neste tópico, descrevem-se os cinco pontos de conformação da pesquisa interdisciplinar, extraídos do texto da dissertação de mestrado da qual origina-se este artigo, denominados pontos de aproximação, destinados a examinar os artigos primeiro, segundo, terceiro, trinta e cinco e trinta e cinco A, da Lei de Diretrizes e Bases da Educação (Lei n. 9.394/1996), a partir dos três fundamentos da juridicidade.

Assim, o primeiro ponto de aproximação refere-se ao artigo primeiro da Lei de Diretrizes e Bases da Educação (Lei n. 9.394/1996) que ao dispor sobre a abrangência da educação considera como processos formativos aqueles "que se desenvolvem na vida 
familiar, na convivência humana, no trabalho, nas instituições de ensino e pesquisa, nos movimentos sociais e organizações da sociedade civil e nas manifestações culturais". ${ }^{6}$

A partir dessa conjuntura, observa-se que entre os processos formativos elencados pelo referido dispositivo legal, somente aqueles que desenvolvem-se nas instituições de ensino e pesquisa são regulados pelo Estado, enquanto os demais, como, por exemplo, vida familiar, convivência humana, movimentos sociais, examinados à luz do "Tripé Jurídico" de Le Roy, regulam-se na esfera da juridicidade.

Nessa ótica, num exercício meramente ilustrativo, destaca-se que o artigo primeiro da Lei de Diretrizes e Bases (Lei n. 9.394/1996) representado na figura do “iceberg jurídico” de Le Roy aparece da seguinte forma:

\section{Representação do artigo primeiro, da Lei de diretrizes e bases da educação}

(Lei n. 9.394/1996), no “iceberg jurídico” de Étienne Le Roy

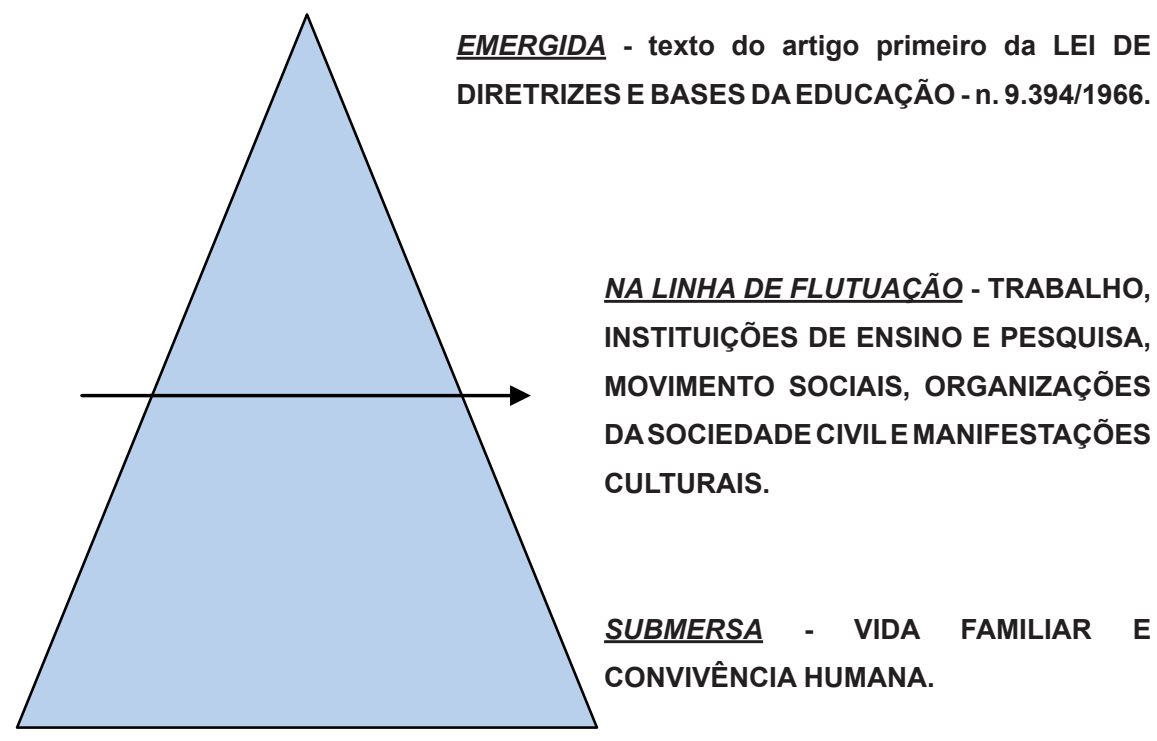

O segundo ponto de aproximação refere-se ao artigo segundo da Lei de Diretrizes e Bases da Educação (Lei n. 9.394/1996), que reproduzindo, na íntegra, o art. 205 da Constituição Federal de 1988, estabelece que a educação é direito de todos e dever do Estado, da família, a ser promovida e incentivada com a colaboração da sociedade.

Art. $1^{\circ}$. A educação abrange os processos formativos que se desenvolvem na vida familiar, na convivência humana, no trabalho, nas instituições de ensino e pesquisa, nos movimentos sociais e organizações da sociedade civil e nas manifestações culturais. (BRASIL, 1996). 
Na mesma linha do raciocínio anterior, pode-se dizer que o artigo segundo da Lei de diretrizes e bases da educação (Lei n. 9.394/1996) ao admitir que a educação é um dever tripartite entre o Estado, a família e a sociedade, analisado sob o ângulo da juridicidade expressa as três dimensões da regulação jurídica, que representadas pelo "iceberg jurídico" estariam: o Estado na parte emergida, a sociedade na linha de flutuação e a família submersa.

O terceiro ponto de aproximação propõe-se a partir da análise conjunta do artigo primeiro, que estabelece a abrangência da educação e da segunda parte do artigo segundo $^{7}$ que dispõe sobre os objetivos da educação, ambos da Lei n. 9.394/1996 (LDB), examinar a relação de complementaridade entre o direito e a juridicidade.

Nessa lógica, observa-se que tanto os processos formativos abrangidos pela educação, previstos no artigo primeiro, quanto os objetivos previstos no artigo segundo, ambos da LDB, exprimem a condição de reciprocidade, de interdependência, do Estado, da família e da sociedade, ou seja, de complementaridade entre o direito oficial e as demais dimensões da juridicidade.

O quarto ponto de aproximação, analisou o artigo terceiro, ${ }^{8}$ da $\mathrm{LDB}$, relativo aos treze princípios concernentes ao ministério do ensino, a partir do argumento de Étienne Le Roy de que o direito institucionalizado é a passagem de tudo que é instituído na esfera da juridicidade.

Em tal situação, pode-se dizer que o artigo terceiro da LDB retrata mais um conjunto de metas ou objetivos a serem alcançados pela administração pública educacional, do que princípios aos educadores.

Nesse sentido, sob a ótica da juridicidade de Le Roy, pode-se dizer que o inciso terceiro, do artigo terceiro, da LDB, ao estabelecer como princípio o "pluralismo de ideias e de concepções pedagógicas" sugere a existência de ideias e concepções pedagógicas, não positivadas, sujeitas a um fluxo de passagem do que está na juridicidade para o domínio do direito estatal.

\footnotetext{
7 Art. $2^{\circ}$. A educação, dever da família e do Estado, inspirada nos princípios de liberdade e nos ideais de solidariedade humana, tem por finalidade o pleno desenvolvimento do educando, seu preparo para o exercício da cidadania e sua qualificação para o trabalho. (BRASIL, 1996).

8 Art. $3^{\circ}$. O ensino será ministrado com base nos seguintes princípios: I - igualdade de condições para o acesso e permanência na escola; II - liberdade de aprender, ensinar, pesquisar e divulgar a cultura, o pensamento, a arte e o saber; III - pluralismo de ideias e de concepções pedagógicas; IV - respeito à liberdade e apreço à tolerância; V - coexistência de instituições públicas e privadas de ensino; VI - gratuidade do ensino público em estabelecimentos oficiais; VII - valorização do profissional da educação escolar; VIII - gestão democrática do ensino público, na forma desta Lei e da legislação dos sistemas de ensino; IX - garantia de padrão de qualidade; X - valorização da experiência extraescolar; XI - vinculação entre a educação escolar, o trabalho e as práticas sociais. XII - consideração com a diversidade étnico-racial. XIII - garantia do direito à educação e à aprendizagem ao longo da vida. (BRASIL, 1996).
} 
Assim, também, o inciso décimo, do mesmo dispositivo legal, ao estipular como princípio do ministério do ensino a "valorização da experiência extraescolar" admite experiências vividas em dimensões não abrangidas pelo direito positivo, denominada, por Étienne Le Roy, como juridicidade.

O quinto ponto de aproximação é traçado, a partir das finalidades do ensino médio, descritas pelo art. 35 da LDB, por meio da análise das expressões "cidadania do educando", na segunda finalidade; e "como pessoa humana, incluindo a formação ética e o desenvolvimento da autonomia intelectual e do pensamento crítico", na quarta finalidade, as quais transcendem a regra posta e adentram às dimensões normativas dos modelos de conduta e comportamento (MCC) e sistemas de disposições duráveis (SDD), propostas por Étienne Le Roy no "tripé jurídico. ${ }^{9}$

Na mesma direção, o parágrafo sétimo, do art. 35-A da LDB, alterado pela Lei n. 13.415/2017, ao estipular que: “Os currículos do ensino médio deverão considerar a formação integral do aluno, de maneira a adotar um trabalho voltado para a construção de seu projeto de vida e para sua formação nos aspectos físicos, cognitivos e socioemocionais", possibilita interpretar que a concretização dos objetivos de "formação integral" e "construção de um projeto de vida" não se subsumem à letra da lei, mas, sim a esfera da juridicidade.

Em síntese, pode-se dizer que os artigos primeiro, segundo, terceiro, trinta e cinco e trinta e cinco A, da LDB, analisados a partir dos três fundamentos da juridicidade, embora limitados à esfera das normas gerais e impessoais (NGI), concebem em seus próprios textos que a Educação é um dever do Estado, da família e da sociedade, e, portanto, que abrange as dimensões regulatórias dos modelos de conduta e comportamento (MCC) e dos sistemas de disposições duráveis (SDD).

3. Mediação no ensino médio público brasileiro: sob o enfoque dos modelos propostos por Étienne Le Roy

Acerca da mediação, destaca-se que o objetivo de Étienne Le Roy não é descobrir outras concepções de mediação, mas, sim, examinar a seguinte afirmação:

9 O ensino médio, etapa final da educação básica, com duração mínima de três anos, terá como finalidades: I - a consolidação e o aprofundamento dos conhecimentos adquiridos no ensino fundamental, possibilitando o prosseguimento de estudos; II - a preparação básica para o trabalho e a cidadania do educando, para continuar aprendendo, de modo a ser capaz de se adaptar com flexibilidade a novas condições de ocupação ou aperfeiçoamento posteriores; III - o aprimoramento do educando como pessoa humana, incluindo a formação ética e o desenvolvimento da autonomia intelectual e do pensamento crítico; IV - a compreensão dos fundamentos científico-tecnológicos dos processos produtivos, relacionando a teoria com a prática, no ensino de cada disciplina. (BRASIL, 1996). 
quando a mediação é considerada um objeto jurídico, destaca mais a juridicidade que o direito.

À vista disso, retomando a visão de que o direito não é autônomo, universal ou isento de efeitos sociais e que a juridicidade transcende o direito e o engloba, Le Roy propõe que se aceite a ideia de que possa existir um campo próprio, bem ou mal identificado ou grosseiramente delimitado, entre o direito e o social não jurídico, no qual se pratica a mediação.

Segundo Le Roy (2012, p. 291), para o desenvolvimento desse raciocínio é "necessário ao menos um pouco de imaginação, mas, sobretudo, vontade e coragem para sair dos caminhos marcados, os quais reproduzem os mesmos esquemas há dezenas de anos, enquanto a sociedade e as normas já estão mudando”.

Dessa forma, interessado na relação entre direito e sociedade, ou, mais precisamente, pela competição que o direito positivo e outras formas mais ou menos próximas, mas não reconhecidas por ele, assumem na reprodução da institucionalização da vida em sociedade, Le Roy (2012, p. 296) analisa três modelos ${ }^{10}$ experimentados pelo autor durante vários anos.

O primeiro modelo, situado na área processual, refere-se à formalização do regulamento das disputas que não tinham tratamento específico pela sociologia do direito e que foram ignoradas pelos teóricos da justiça. Esse modelo, segundo Le Roy (2012, p. 296), permite desvincular o direito da mediação, como imagem espontânea, conforme legado recebido da formação jurídica ocidental.

Aos olhos de Le Roy (2012, p. 291), a influência do direito imprime à mediação um caráter juridicizante que não permite a apreensão da essência da mediação, de um modo mais consequente.

A partir desse raciocínio, o autor extrai três observações, sendo a primeira, de que a mediação não é justiça, nem mesmo de forma amena (même douce), contrapondose ao pensamento de Jean Pierre Bonafé-Schmitt (1992, p. 279) para quem a mediação é muitas vezes apresentada como uma alternativa à justiça, uma outra justiça, uma justiça branda, baseada na busca de soluções negociadas pelas pessoas em conflito.

A segunda observação de Le Roy (2012, p. 301) é no sentido de que a mediação não precisa do direito, eis que dispõe de seus próprios suportes, com destaque

\footnotetext{
10 Conforme interpretado por Orlando Villas Bôas Filho (2017, p. 1.128-1.129), os modelos analisados por Étienne Le Roy podem ser desdobrados em três momentos fundamentais na produção do autor sobre a mediação. O primeiro pelo artigo intitulado Médiation mode d'emploi, de 1995, na revista Droit et société; o segundo, pelo artigo La médiation comme "dialogie” entre les ordonnancements de regulation sociale, no livro Diversité culturelle et médiation: pour quelle Société? e o terceiro no artigo Place de la juridicité dans la médiation, no n. 4 de Jurisprudence: revue critique.
} 
para os sistemas de disposições duráveis (habitus), ao gestual e as técnicas de corpo para formalizar a solução.

$\mathrm{Na}$ terceira observação, o autor enfatiza que a mediação responde a um problema de reconhecimento de uma relação social. Segundo Le Roy o processo negociado tem a missão "educativa" de fazer acontecer ou restaurar uma relação.

Nessa perspectiva, Le Roy (2012, p. 302) ressalta que apesar de solucionar controvérsias, a mediação não interfere no conflito, dito litígio, que diante das suas especificidades deve ser tratado pelo processo judicial.

O segundo modelo denominado pelo autor como um fenômeno novo (início do século XXI) refere-se à desconstrução da percepção de que somente uma programação negociada pode tornar-se mestra de um conceito que regula as sociedades contemporâneas. Le Roy (2012, p. 296) considera que esse modelo propõe uma leitura variada da complexidade dos processos contemporâneos.

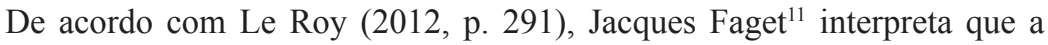
mediação, como modelo conciliador, associou-se a três outros dispositivos: o modelo retributivo, fundado sobre a culpa e a punição; o modelo terapêutico, sobre a necessidade de cuidado e o modelo restitutivo ou compensador, ligado ao reconhecimento de um prejuízo a reparar.

Nessa ótica, observando as mudanças sofridas pela mediação, denominadas por Faget como "processus" (imposto, negociado e aceito), Le Roy (2012, p. 305) observa que em 1985, no âmbito do Juizado de Menores, a mediação que, era tratada como princípio da organização judiciária (justiça negociada e justiça imposta), passa, em 1989, a ser considerada como ordem social (imposição, negociação, aceitação) e, por fim, como responsabilidade social.

Assim, no horizonte de que a mediação é dinâmica e progressiva, Le Roy indica quatro tipos ideais de ordenamentos sociais para solução de conflitos: a) ordenamento aceito - as divergências não se transformam em conflitos, uma vez que as partes resolvem o conflito pelo acordo; b) ordenamento contestado - os conflitos terminam pela vitória do mais forte ou do mais hábil; c) ordenamento negociado - quando ocorre a intervenção de um terceiro para a solução dos conflitos e no qual as normas jurídicas constituem modelos não imperativos; e d) ordenamento imposto - transformação dos conflitos em litígios resolvidos mediante a aplicação do direito positivo vigente e de uma decisão judicial.

\footnotetext{
11 Jacques Faget, é diretor de pesquisa no CNRS (Centre Emile Durkheim), lecionando nas Universidades de Bordeaux, Poitiers, Paris V, Barcelona, Pádua, Bruxelas. Praticante de mediação na Associação de Mediação Alternativa, é instrutor de mediação na França, Suíça, Bélgica, Itália, Espanha e México. Disponível em: https://www.lecteurs.com/auteur/jacques-faget/3114403. Acesso em: 13 out. 2018.
} 
O esquema abaixo desenvolvido por Le Roy (2012, p. 307) tem a finalidade de demonstrar o deslocamento da mediação de uma ordem negociada a um conceito-reitor central de regulação jurídica:

\section{ORDENAMENTOS SOCIAIS}

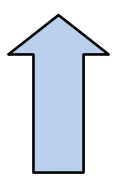

Negociado
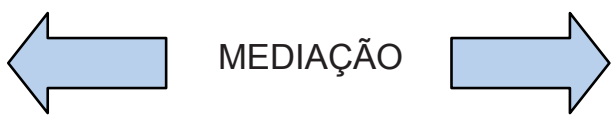

Aceito

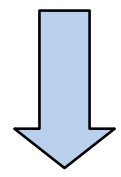

\section{Contestado}

Esclarecendo que o mérito desse esquema é revelar as ambiguidades de uma mediação, Le Roy (2012, p. 307) ressalta que mesmo na condição de ordem negociada, a mediação pode ser utilizada pelo ordenamento imposto, para aceitar a intervenção do magistrado ou uma decisão judicial.

Le Roy (2012, p. 307) confirma a hipótese dada, trazendo como exemplo o mediador penal que, atuando como agente de aplicação de uma decisão judiciária, sob o controle do magistrado, personifica a lei para o delinquente, sendo, nesse aspecto, a mediação utilizada como outra forma de justiça e não, propriamente, como mediação.

No terceiro modelo referente à análise dos processos de trabalho, Le Roy (2012, p. 309) busca compreender como os dispositivos de regulação mudam e quais as consequências tiradas pelos atores e, a partir daí, melhor orientar as políticas de reformulação das instituições.

Nessa perspectiva, o autor considera como principais variáveis para evidenciar as regras do jogo da mediação e juridicidade: em primeiro plano - o status dos atores, seus recursos, suas condutas, suas lógicas de racionalização para a ação e, em segundo - as escalas espaciais, os processos temporais, as arenas (fóruns) de confrontação e de negociação.

Le Roy (2012, p. 310) destaca que as análises desenvolvidas nos primeiros trabalhos sobre a conciliação, de 1988, mostraram que a negociação se manifesta, institucionalmente ou não, sob três vias: a) uma justiça de gabinete (justice de cabinet), 
situada no Judiciário; b) a conciliação (e a mediação penal, no sentido francês) situada nas margens da instituição e à sombra dos tribunais; e c) a mediação (do ponto de vista norteamericano) ou arbitragem como uma alternativa mais ou menos autônoma, subavaliada na França.

Para o antropólogo francês (LE ROY, 2012, p. 310), tais vias não são, necessariamente, concorrentes, pois, respondem por funções teoricamente complementares a serem cumulativamente consideradas por uma política pública judiciária que pretenda revalorizar a justiça negociada.

Conforme interpreta Villas Bôas Filho (2017, p. 1.128), dos três modelos apresentados por Le Roy, o primeiro pretende promover a desconstrução da representação formalista e juridicizante que atrela a mediação ao campo do direito. O segundo busca demonstrar a progressiva transformação da mediação em um conceito central da regulação social contemporânea e o terceiro propõe, a partir da hipótese da juridicidade, uma melhor compreensão das práticas envolvidas na mediação.

Nesse contexto, com base na teoria da juridicidade, uma visão dialogal do mundo corresponderia à transposição dos mecanismos de resolução e/ou administração de conflitos do processo autoritário (a adjudicação) pelo processo dialogal, não autoritário (a mediação).

No que refere-se às práticas, às formas e aos procedimentos da mediação, Étienne Le Roy (1995, p. 46-47) descreve-os em quatro modelos de mediação, assim denominados: a) como prática de intervenção em uma controvérsia; b) como procedimento de gestão de um conflito; c) como procedimento parajudicial de composição de litígios; e, d) como ideologia da pacificação social e projeto de sociedade.

Nessa situação, destaca-se que Le Roy (1995, p. 46-47) considera: a) controvérsia como uma oposição aberta entre dois ou mais atores (indivíduos ou grupos), compartilhando um mínimo de referências comuns que permitirão a elaboração de um acordo; b) conflito, como uma oposição aberta igual à controvérsia, porém, público, conhecido pelas partes, conhecido até midiaticamente, e c) litígio como o conflito levado ao Judiciário.

Quanto aos objetivos a serem alcançados pelos modelos de mediação Le Roy (1995, p. 46-47) observa que, no primeiro procedimento, a mediação como prática de intervenção em uma controvérsia, o objetivo principal é a restauração do vínculo social outrora esgarçado, sendo que, nesse caso, não há imposição quanto à realização do acordo.

No segundo modelo, denominado a mediação como procedimento de gestão de um conflito, o fato em disputa é de conhecimento público e até mesmo difundido midiaticamente e o objetivo a ser alcançado é a compreensão das condições que ensejaram o conflito e, a partir daí, abrir caminho para uma composição entre as partes. 
No terceiro modelo, intitulado a mediação como procedimento parajudicial de resolução de litígios, relativo aos procedimentos judiciais formais, a meta prioritária é a realização de acordos em processos e instâncias previstas e admitidas pelo Judiciário.

Por fim, o quarto e último modelo, designado mediação como ideologia da pacificação social e projeto da sociedade, implica em três realidades, a saber: a) uma ideologia de práticas profissionais fora do campo judicial; b) uma filosofia de ação social e vida em sociedade com o que pode assumir valores específicos hierarquicamente organizados; e c) um projeto político como alternativa às atuais modalidades de organização de sociedades construídas em torno do consumismo, do capitalismo, do Estado e individualismo.

Na sequência, apresentam-se os resultados obtidos por meio da análise comparativa entre dispositivos legislativos relativos ao ensino médio público e os quatro modelos de mediação propostos por Étienne Le Roy, com base em três critérios de adequação: a) as condições do conflito; b) os objetivos a serem alcançados e c) a solução encontrada.

3.1. Bullying - programa de combate à intimidação sistemática e a mediação como prática de intervenção em uma controvérsia

O primeiro cenário analisou o parágrafo primeiro, do artigo primeiro e artigo quarto da Lei n. 13.185/2015 que instituiu o Programa de Combate à Intimidação Sistemática, conhecida como Lei do “Bullying” sob a ótica do modelo da mediação como prática de intervenção em uma controvérsia.

Nesse sentido, conforme definido pelo parágrafo primeiro, do artigo primeiro da Lei n. 13.185/2015, o bullying é todo ato de violência física ou psicológica, intencional e repetitivo que ocorre sem motivação evidente, praticado por indivíduo ou grupo, contra uma ou mais pessoas, com o objetivo de intimidá-la ou agredi-la, causando dor e angústia à vítima, em uma relação de desequilíbrio de poder entre as partes envolvidas, ou seja, aos moldes do que descreve Le Roy, trata-se de um conflito próprio de relações sociais continuadas, com destaque para os ambientes escolares.

No que refere-se aos objetivos ao serem alcançados, Le Roy sublinha que esse modelo de mediação destina-se a compreender a disputa e as condições necessárias para facilitar a comunicação bloqueada ou rompida.

A respeito da solução estatal, observa-se que o artigo quarto ${ }^{12}$ do referido dispositivo legal elenca nove objetivos, dos quais destaca-se o inciso sétimo relativo à

12 Art. $4^{\mathrm{o}}$. Constituem objetivos do Programa referido no caput do art. $1^{\mathrm{o}}$ : I - prevenir e combater a prática da intimidação sistemática (bullying) em toda a sociedade; II - capacitar docentes e equipes pedagógicas para 
promoção da cidadania, da empatia e da alteridade, passíveis de serem obtidos por meio da mediação.

3.2. Reforma do ensino médio - exposição de motivos da medida provisória n. 746/2016 e a mediação como procedimento de gestão de um conflito

Para o segundo cenário buscou-se analisar o texto da Exposição de Motivos da Medida Provisória n. 746/2016, convertida na Lei n. 13.415/2017, que culminou com a inserção do artigo 35-A, na Lei de Diretrizes e Bases da Educação (Lei n. 9.394/1996), conhecida como a Reforma do Ensino Médio, a partir do modelo de mediação como procedimento de gestão de um conflito.

Com efeito, observou-se que as conclusões constantes dos itens 4, 5 e 6 do texto da Exposição de Motivos, quais sejam: a) que os jovens de baixa renda não veem sentido no que a escola ensina; b) que um elevado número de jovens encontra-se fora da escola e aqueles que fazem parte dos sistemas de ensino não possuem bom desempenho educacional; e c) que a falta de escolaridade reflete diretamente nos resultados sociais e econômicos do país, podem caracterizar um conflito de oposição aberta, público e fora do Judiciário, e, portanto, adequado para o modelo proposto.

No que se refere aos objetivos a serem alcançados, Le Roy enfatiza que esse modelo visa compreender as causas que ensejaram o conflito e, a partir daí, criar caminhos possíveis para uma solução consensuada.

No caso, a solução estatal encontrada, conforme extrai-se do item 13, do texto sob análise, foi a alteração legislativa, com a criação da Base Nacional Comum Curricular, por meio do art. 35-A da Lei de Diretrizes e Base da Educação (Lei n. 9.394/1996).

Nesse cenário, vale cogitar, a título de caminho para solução dos problemas diagnosticados no texto da Exposição de Motivos, a criação de câmaras de prevenção e

a implementação das ações de discussão, prevenção, orientação e solução do problema; III - implementar e disseminar campanhas de educação, conscientização e informação; IV - instituir práticas de conduta e orientação de pais, familiares e responsáveis diante da identificação de vítimas e agressores; V - dar assistência psicológica, social e jurídica às vítimas e aos agressores; VI - integrar os meios de comunicação de massa com as escolas e a sociedade, como forma de identificação e conscientização do problema e forma de preveni-lo e combatê-lo; VII - promover a cidadania, a capacidade empática e o respeito a terceiros, nos marcos de uma cultura de paz e tolerância mútua; VIII - evitar, tanto quanto possível, a punição dos agressores, privilegiando mecanismos e instrumentos alternativos que promovam a efetiva responsabilização e a mudança de comportamento hostil; IX - promover medidas de conscientização, prevenção e combate a todos os tipos de violência, com ênfase nas práticas recorrentes de intimidação sistemática (bullying), ou constrangimento físico e psicológico, cometidas por alunos, professores e outros profissionais integrantes de escola e de comunidade escolar. (BRASIL, 2015). 
resolução administrativa de conflitos, conforme previsto pelo art. 32, da Lei n. 13.140/2015, que dispõe sobre a mediação entre particulares e no âmbito da administração pública.

Nesse raciocínio, o Conselho Nacional da Educação, órgão do Ministério da Educação e Cultura do Brasil, criado pela Lei n. 9.131/1995, e que possui, entre outros, o compromisso de instaurar um diálogo efetivo, articulado e solidário, com todos os sistemas de ensino (em nível federal, estadual e municipal), em regime de colaboração e de cooperação, poderia, em tese, ser visto, como um espaço para desenvolvimento do procedimento de gestão de conflitos, conforme descrito por Étienne Le Roy.

\subsection{Justiça Restaurativa - Resolução n. 225/2016 do CNJ - e a mediação como procedimento parajudicial de resolução de litígios}

A terceira investigação, diz respeito à mediação como procedimento parajudicial de resolução de litígios, realizada no âmbito do Judiciário, para análise da Resolução n. 22/2016 do Conselho Nacional de Justiça, que criou a política nacional da justiça restaurativa, definida como um conjunto ordenado e sistêmico de princípios, métodos, técnicas e atividades próprias, para tratar, prioritariamente, conflitos que envolvam adolescentes em conflito com a lei.

Nesse quadro, pode-se dizer que a justiça restaurativa, conforme regulada pela Resolução n. 225/2016 do Conselho Nacional de Justiça, conforma-se com o modelo de mediação, descrito por Étienne Le Roy como procedimento parajudicial de resolução de litígios, eis que ambos visam à realização de acordo, no âmbito do Judiciário.

Segundo interpretado por Villas Bôas Filho (2017, p. 1.135), os quatro problemas destacados por Le Roy para esse modelo são: a) a função do mediador de terceiro neutro esvazia-se diante do juiz que o subordina; b) a mediação torna-se uma subjustiça diante das implicações da administração judiciária; c) a perda de fronteira que separa a mediação, a conciliação e a arbitragem; e d) a escolha do mediador é imposta às partes pelo magistrado, e, em certas circunstâncias ao próprio mediador.

Acerca da função do mediador ou facilitador restaurativo, conforme previsto pelo art. 13 da Resolução n. 225/2016 do Conselho Nacional de Justiça, "Somente serão admitidos, para o desenvolvimento dos trabalhos restaurativos ocorridos no âmbito do Poder Judiciário, facilitadores previamente capacitados, ou em formação, nos termos do Capítulo VI, desta Resolução", ou seja, não possui grau de neutralidade em face da autoridade estatal, conforme o primeiro problema apontado por Le Roy.

Quanto à condição ancilar da mediação como uma subjustiça, conforme denunciado pelo autor francês, pode-se dizer que, no âmbito da Resolução n. 225/2016 do Conselho Nacional de Justiça, essa é a hipótese que se opera quando se trata de procedimento restaurativo ocorrido durante o trâmite processual penal. 
Entretanto, no caso da ocorrência do procedimento restaurativo antes da judicialização, a submissão do acordo e do plano de ação ao Judiciário para homologação é facultativa, conforme previsto pelo artigo décimo segundo, da mesma resolução.

Quanto à escolha do mediador ser imposta às partes pelos magistrados e em certas circunstâncias ao próprio mediador, ou seja, em prejuízo ao princípio da neutralidade do mediador, conforme observa Le Roy, pode-se dizer que na realidade brasileira a situação é semelhante.

Isto porque, conforme extrai-se do inciso III, do artigo sexto, da Resolução n. 225/2016, do Conselho Nacional de Justiça, cabe aos Tribunais de Justiça Estaduais, a formação e manutenção de equipe de facilitadores restaurativos arregimentados entre servidores do próprio quadro funcional ou designados pelas instituições conveniadas.

3.4. Objetivos da Educação nacional - art. 205 da Constituição Federal de 1988 - e a mediação como ideologia da pacificação social e projeto da sociedade

No que se refere ao quarto modelo, da mediação como ideologia da pacificação social e projeto da sociedade, pretende-se examinar os três objetivos da Educação nacional: o pleno desenvolvimento da pessoa, seu preparo para o exercício da cidadania e sua qualificação para o trabalho, previstos no art. 205, da Constituição Federal de 1988, a partir da afirmação de Le Roy (2012, p. 319) de que "A mediação é, primeiramente, uma escola de cidadania com senso de responsabilidade, de conhecimentos de competências, de respeito pelo outro e de gosto pela decisão".

Em tal caso, é possível extrair a primeira conexão entre a mediação e o ensino médio público, dos próprios textos, pois, enquanto, de um lado, o preceito constitucional estabelece o preparo para o exercício da cidadania como um objetivo da educação nacional, de outro, Le Roy define a mediação como uma escola de cidadania.

No horizonte de que o exercício da cidadania implica em um processo contínuo de construção coletiva de uma sociedade mais justa e solidária, pode-se dizer que educação e a mediação são temas relacionados à cultura de paz.

Nessa lógica, no âmbito do Direito Constitucional, destaca-se que o autor Paulo Bonavides (2018, p. 595), ao analisar a quinta geração de direitos fundamentais, concebe o direito à paz como um direito imanente à vida e indispensável ao progresso de todas as nações, grandes e pequenas, em todas as esferas.

Bonavides (2018, p. 608) sublinha que, se antes a paz era tida, teoricamente, como direito fundamental, na atualidade é erguida à categoria de direito positivo. E se ontem a paz era um conceito filosófico, hoje ela é um conceito jurídico, o que justifica, ainda mais, que seja acolhida pelas Constituições. 
De acordo com Bonavides (2018, p. 595), há uma espécie de "poder constituinte moral" que busca no reconhecimento normativo, a criação de um novo direito, um direito de garantia e sobrevivência do homem na idade dos artefatos nucleares e da explosão tecnológica.

Assim sendo, sob o enfoque da teoria da juridicidade de Étienne Le Roy, observa-se, primeiramente, que o "poder constituinte moral", descrito por Bonavides, se expressa mais nas dimensões dos modelos de conduta e comportamento e dos sistemas de disposições duráveis.

E, em segundo lugar, que ao impulsionar a paz para uma normatização constitucional, o "poder constituinte moral" pretende passar o que está na juridicidade para a ordem imposta.

No mesmo sentido, observa-se que o modelo da mediação como ideologia da pacificação social e projeto da sociedade, como visto por Le Roy, ao mobilizar, de um lado, os valores morais da disponibilidade, da responsabilidade e altruísmo e, de outro, os valores sociais da solidariedade, da dignidade, e da liberdade, conforma-se, em grande medida, nas dimensões não impostas pelo direito oficial.

Nessa perspectiva, ainda no intuito de analisar os três objetivos da educação nacional, previstos no texto constitucional, sob a ótica do modelo da mediação como ideologia da pacificação social e projeto de sociedade, pode-se dizer que a solução normativa estatal tem sido insuficiente para superar questões como adolescentes em conflito com a lei, evasão e repetência escolar.

Em tal caso, destaca-se que a autora Camila Nicácio (2012, p. 276), com suporte no pensamento de Étienne Le Roy, interpreta que a mediação, como um instrumento de socialização jurídica, pode contribuir não somente para uma mudança quanto à forma de resolver conflitos, mas, de modo mais englobante, também para reconfiguração da relação de indivíduos e grupos com o próprio "direito".

Nicácio (2012, p. 276) explica não se tratar de um “direito” oficial fixado em leis e códigos, imposto pela coerção legítima do Estado, mas um direito mais abrangente identificado na noção de "juridicidade" de Le Roy, como um conjunto de registros normativos que coexistem, em tensão, com o direito dos códigos.

Resumindo, à vista dos quatro cenários de análise acima, tem-se que a abordagem teórico-prática da mediação desenvolvida por Étienne Le Roy pode contribuir para o desvelamento de novas ferramentas de pesquisa para questões sociais complexas como a educacional brasileira. 


\section{Conclusão}

Como visto, este artigo refere-se a parte de uma pesquisa interdisciplinar, entre o Direito Constitucional, no âmbito do direito à Educação e a Antropologia Jurídica, sob o enfoque do pensamento de Étienne Le Roy, destinada a demonstrar que a mediação ocorre mais nos limites dos modelos de conduta e comportamentos (MCC) e dos sistemas de disposições duráveis (SDD), do que das normas gerais e impessoais (NGI), do direito estatal.

Dos resultados obtidos, ainda que parciais, extrai-se que a comprovação da hipótese inicial demanda maior aprofundamento teórico e empírico. Contudo, a partir dos mesmos resultados, é possível dizer que os cinco pontos de aproximação revelam que a pesquisa interdisciplinar, na área do Direito, pode propiciar o desenvolvimento de novas formas de análise da regulação jurídica do Brasil.

No mesmo horizonte, tem-se que as análises dos dispositivos legais, a partir dos modelos de mediação propostos por Étienne Le Roy, desvelam o potencial da Antropologia Jurídica no fornecimento de aportes teóricos inovadores para a ampliação e aprofundamento das pesquisas de questões sociais intrincadas como, por exemplo, a educacional brasileira.

Ainda, acerca dos resultados alcançados, pode-se afirmar que a Teoria do Multijuridismo, proposta por Étienne Le Roy, constitui-se em um arcabouço teórico passível de ser mobilizado para compreensão de outros problemas de grande interesse da sociedade brasileira, tais como: a posse e propriedade de terras, gênero, raça e etnia.

No que se refere ao pensamento de Étienne Le Roy sobre a mediação, as pesquisas indicam tratar-se de um conjunto de conhecimentos teórico e prático desenvolvidos ao longo de várias décadas, capaz de contribuir para o estudo e as pesquisas de políticas públicas relativas ao tratamento adequado dos conflitos.

Por fim, a afirmação de Étienne Le Roy de que a mediação, para além de um método alternativo de solução de conflitos, é uma escola de cidadania, motiva a autora a continuar a pesquisa da hipótese inicialmente proposta, de que a mediação ocorre mais nos limites dos costumes e dos hábitos do que nas regras da lei.

São Paulo, 23 de abril de 2019.

\section{Referências}

BONAFÉ-SCHMITT, Jean-Pierre. Os modelos de mediação: modelos latinos e anglo-saxões de mediação. Revista Meritum, Belo Horizonte, v. 7, n. 2, p. 181-227, jul./dez. 2012.

BONAVIDES, Paulo. Curso de direito constitucional. 33. ed. São Paulo: Malheiros, 2018. 
BOURDIEU, Pierre. A economia das trocas simbólicas. Introdução, organização e seleção Sergio Miceli. 8. ed. São Paulo: Perspectiva, 2015. (Coleção estudos; 20 / dirigida por J. Guinsburg).

BRASIL. Lei n. 9.394, de 20 de dezembro de 1996. Estabelece as diretrizes e bases da educação nacional. Portal do Planalto, Brasília, DF, 1996. Disponível em: http://www.planalto.gov.br/ ccivil_03/leis/19394.htm.

BRASIL. Lei n. 13.185, de 6 de novembro de 2015. Institui o programa de combate à intimidação sistemática (Bullying). Portal do Planalto, Brasília, DF, 2015. Disponível em: http://www.planalto. gov.br/ccivil_03/_ato2015-2018/2015/lei/113185.htm.

EBERHARD, Christoph. Para uma teoria jurídica intercultural: o desafio dialógico. Revista Direito e Democracia, Canoas, v. 3, n. 2, p. 489-530, jul./dez. 2002.

FRANCE. Code civil (version consolidée au 18 février 2015). WIPO IP Portal, Geneva, 2015. Disponível em: https://wipolex.wipo.int/es/legislation/details/14526.

LE ROY, Étienne. La médiation mode d'emploi. Revue Droit et Société, Paris, n. 29, p. 39-55, 1995.

LE ROY, Étienne. Le jeu des lois: une anthropologie “dynamique” du Droit. Paris: Libraire Générale de Droit et de Jurisprudence, 1999. (Série anthropologique, 28).

LE ROY, Étienne. O lugar da juridicidade na mediação. Revista Meritum, Belo Horizonte, v. 7, n. 2, p. 289-324, jul./dez. 2012.

NICÁCIO, Camila Silva. A mediação diante da reconfiguração do ensino e da prática do direito: desafios e impasses à socialização jurídica. Revista Meritum, Belo Horizonte, v. 7, n. 2, p. 249-288, jul./dez. 2012.

PRUDENTE, Eunice Aparecida de Jesus. Educação em direitos: um caminho para a igualdade racial. Revista Brasileira de Filosofia, São Paulo, ano 60, n. 236, p. 35-72, jan./jun. 2011.

ROULAND, Norbert. Anthropologie juridique. Paris: Presses Universitaires de France, 1988.

ROULAND, Norbert. Nos confins do direito: antropologia jurídica da modernidade. Tradução Maria Ermantina de Almeida Prado Galvão. 2. ed. São Paulo: Martins Fontes, 2008. (Coleção justiça e direito).

SIX, Jean-François. Dinâmica da mediação. Tradução de Águida Arruda Barbosa, Eliana Riberti Nazareth e Giselle Groeninga de Almeida. Belo Horizonte: Del Rey, 2001.

VILLAS BÔAS FILHO, Orlando. A mediação em um campo de análise interdisciplinar: o aporte da teoria do multijuridismo de Étienne Le Roy. Revista Estudos Institucionais, Rio de Janeiro, v. 3, n. 2, p. 1.112-1.162, 2017. Disponível em: https://estudosinstitucionais.com/REI/article/view/205. Acesso em: 24 ago. 2018. 
VILLAS BÔAS FILHO, Orlando. A regulação jurídica para além de sua forma ocidental de expressão: uma abordagem a partir de Étienne Le Roy. Revista Direito \& Práxis, Rio de Janeiro, v. 6, n. 12, p. 159-195, 2015.

VILLAS BÔAS FILHO, Orlando. Ancient Law: um clássico revisitado 150 anos depois. Revista da Faculdade de Direito da Universidade de São Paulo, São Paulo, v. 106/107, p. 527-562, jan./ dez. 2011/2012.

VILLAS BÔAS FILHO, Orlando. Juridicidade: uma abordagem crítica à monolatria jurídica enquanto obstáculo epistemológico. Revista da Faculdade de Direito da Universidade de São Paulo, São Paulo, v. 109, jan./dez. 2014. 